\title{
$\begin{array}{lllllll}\mathbf{J} & \mathbf{o} & \mathbf{u} & \mathbf{r} & \mathbf{n} & \mathbf{a} & \mathbf{l}\end{array}$ \\ Nonlinear Science
}

DEDICATION

\section{J.E. Marsden Memorial Issue}

Published online: 16 August 2012

(C) Springer Science+Business Media, LLC 2012

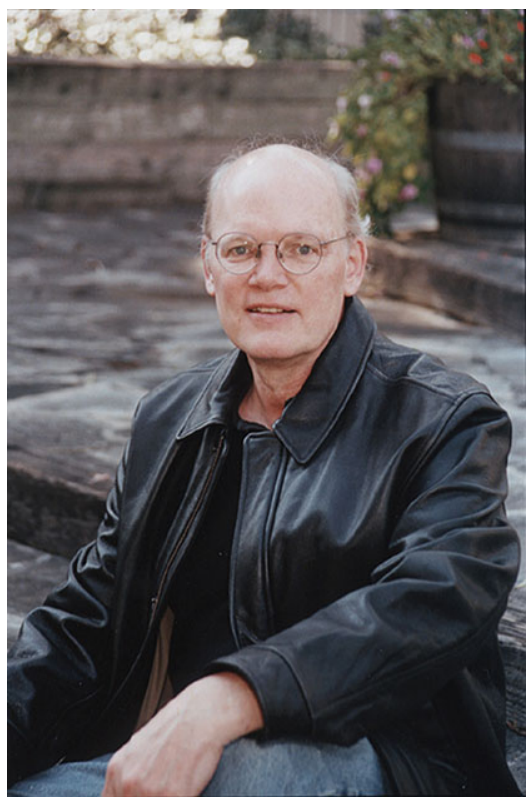

We dedicate this special issue of The Journal of Nonlinear Science to the memory of Jerry Marsden (1942-2010), who guided the Journal as its Editor-in-Chief for many years. He would have been 70 on August 17, 2012.

Anthony M. Bloch and Tudor S. Ratiu, Guest Editors

Paul K. Newton, Managing Editor

Katepalli R. Sreenivasan, Editor-in-Chief 